\title{
Desvinculação da experiência transexual do diagnóstico psicanalítico de psicose
}

\author{
Disentailing the transsexual experience of the psychoanalytic diagnosis of psychosis \\ Desvinculanción de la experiencia transexual del diagnóstico psicoanalítica de psicosis \\ Rafael Kalaf Cossi \\ Instituto de Psicologia da Universidade de São Paulo (USP)
}

\begin{abstract}
Resumo
Este artigo pretende contribuir para a pesquisa sobre a transexualidade em psicanálise e abrir novas possibilidades de compreensão deste quadro clínico. As teses de Robert Stoller - clássicas sobre o tema -, assim como os trabalhos de psicanalistas lacanianos, tais como os de Safouan (1979) e Czermack (1991), relegam a transexualidade ao campo da patologia. Tais psicanalistas lacanianos defendem uma clínica que restringe a transexualidade à psicose, pois creem que, neste caso, recaem a Verwerfung e a foraclusão do Nome-do-pai. Este trabalho pretende expor equívocos nos fundamentos desta concepção. Trata-se de mostrar que a Verleugnung, mecanismo em jogo no psiquismo comum e no modo atual de funcionamento do social, opera também na transexualidade. Desta forma, este artigo pode desempenhar um importante papel para a desarticulação da transexualidade do diagnóstico psicanalítico de psicose e do campo da psicopatologia.

Palavras-chave: Transexualidade; Psicanálise; Psicose; Verleugnung.
\end{abstract}

\begin{abstract}
This paper aims to contribute to the current debate about the psychoanalytic view on transsexuality and, by doing so, open new possibilities for clinical practices connected to the issue. Robert Stoller - whose ideas became paradigmatic on the field - and lacanian psychoanalysts, such as Safouan (1979) and Czermack (1991), claim that there is a necessary association between transsexuality and pathology. These lacanian schollars support a clinical praxis that restricts transsexutality to psychoses, because they believe that, in those cases, the psychic mechanism at stake is only the Verwerfung and foreclosure of the Name of the Father. This work aims to expose failures on the justification of this thesis. It intends to show that Verleugnung, a mechanism that operates in non-pathological psychic and in current social experiences, is also present on transsexuality. So, this paper can play an important role on a process of disassociation of transsexuality and the clinical diagnosis of psychosis and the field of pathology. Key-words: Transsexuality; Psychoanalysis; Psychosis; Verleugnung.
\end{abstract}

\begin{abstract}
Resumen
Este artículo pretende contribuir al debate actual sobre la transexualidad en el psicoanálisis y abrir nuevas posibilidades para la comprensión de este cuadro clínico. Robert Stoller - cuyas ideas se convirtieron en paradigma en el campo - y psicoanalistas lacanianos, como Safouan (1979) y Czermack (1991), afirman que existe una relación necesaria entre la transexualidad y la patología. Estos psicoanalistas lacanianos apoyan una praxis clínica que restringe transexualidad a las psicosis, porque creen que, en esos casos, el mecanismo psíquico en juego es sólo el Verwerfung y la forclusion del Nombre del Padre. Este artículo tiene como objetivo exponer las fallas en la justificación de esta tesis. También tiene la intención de mostrar que la Verleugnung, mecanismo en juego en la psique común y el modo de funcionamiento actual de la sociedade, también está presente en la transexualidad. Por lo tanto, esta investigación puede desempeñar un papel importante en un proceso de disociación de la transexualidad y el diagnóstico clínico de la psicosis y el campo de la patología.

Palabras- clave: Transexualidad; Psicoanálisis; Psicosis; Verleugnung.
\end{abstract}

\section{Introdução}

A transexualidade interroga de maneira radical as noções de identidade e diferença sexual, normalidade e patologia. O que faz de um homem, um homem e de

\section{Endereços:}

Instituto de Psicologia da Universidade de São Paulo: Endereço: Av. Prof. Mello Moraes, 1721 - CEP: 05508-030 - São Paulo, SP - Brasil.

Residencial: Rua Dom Roberto Pinarello de Almeida, 160, bloco 3 ap. 201-CEP: 13207-655-Jundiaí-SP

Consultório: Rua Prudente de Morais, 1116-CEP: 13201-004Jundiaí-SP uma mulher, uma mulher? A aparência física parece ser o primeiro critério a determinar o posicionamento do sujeito na diferença sexual, mas o sexo do corpo não determina o gênero sexual do sujeito, tal como se evidencia na experiência transexual.

Fundamentalmente, a transexualidade é um fenômeno cuja problemática se manifesta no âmbito da identidade sexual. Aqui o sujeito padece de uma discordância: enquanto seu corpo indica corresponder a um sexo, masculino ou feminino, ele diz identificarse ao sexo oposto. Como forma de adequar seu corpo ao gênero, muitos transexuais recorrem a intervenções 
hormonocirúrgicas e solicitam a mudança de nome.

A partir dos anos 50, deu-se início à divulgação dos casos de transexualidade e, desde então, o interesse da mídia pelo assunto é cada vez maior. De lá até os dias de hoje, apesar de continuarem marginalizados socialmente, avançou-se em alguns pontos e direitos foram conquistados: da clandestinidade das primeiras intervenções cirúrgicas até recentemente, em 2008, quando, no Brasil, o SUS passou a incluir os tratamentos hormonocirúrgicos como terapêutica a ser oferecida aos sujeitos transexuais; da invisibilidade como cidadãos, eles chegam na atualidade a ocupar cargos na política pública na Europa e nos EUA.

Foi a medicina, e dentro dela a psiquiatria, que se apropriou inicialmente das questões relacionadas à transexualidade. No âmbito médico, prevalece o ponto de vista de que estes sujeitos são portadores de um distúrbio ou transtorno de identidade sexual, pois seu sexo biológico e sua identidade sexual estão em desacordo. A forma de reparar tal erro se daria com o tratamento hormonocirúrgico, como pregava Benjamin (1966), precursor do estudo e da clínica médica da transexualidade.

As hipóteses diagnósticas aqui são bastante variadas, desde disfunções neurológicas e endócrinas às que a encaram como fruto de fatores psíquicos ou sociais. Saadeh (2004) aponta que as pesquisas que se pautam em fatores biológicos para explicar a transexualidade prosseguem, mas até hoje não obtiveram resultados conclusivos.

As pesquisas em psicologia e psicanálise também não são definitivas quanto a sua clínica. Neste trabalho, tentaremos descrever o que há de fundamental na clínica da transexualidade a partir da perspectiva da psicanálise lacaniana. Inicialmente, voltar-nos-emos para a teoria que Stoller desenvolve sobre a formação da identidade sexual e a transexualidade, que serve como ponto de partida do estudo deste quadro clínico por importantes autores lacanianos, tais como Safouan (1979), Czermak (1991) e Frignet (2002): a experiência transexual é entendida por estes últimos como um fenômeno psicótico, fruto da foraclusão do Nome-do-Pai. Como meio de desvincular a transexualidade do âmbito da patologia e do rótulo de anormalidade, lançaremos mão do mecanismo da Verleugnung (desmentido), entendido não como elemento determinante da estrutura perversa, mas como um mecanismo em uso por todo e qualquer sujeito e em ação no tempo atual — a partir desta perspectiva, levantaremos hipóteses sobre como tal operador se manifesta na transexualidade.

\section{O transexual stolleriano}

Robert J. Stoller, psiquiatra e psicanalista, foi tido como o maior especialista americano em transexualidade e o teórico responsável por ter trazido para a psicanálise, em 1968, a noção de "gênero" (gender). Suas teses, inovadoras e polêmicas, revigoraram as interrogações freudianas acerca da sexualidade (Roudinesco e Plon, 1998, p. 730-731).

$O$ conceito de gênero na obra de Stoller reúne aspectos psicológicos, sociais, históricos associados à masculinidade, por um lado e à feminilidade, por outro. $\mathrm{O}$ forjamento desta noção decreta em definitivo que o sexo, no sentido anatômico, diferencia-se da identidade sexual e que tais elementos não são naturalmente correspondentes. Para Stoller (1982), a não coerência entre sexo e gênero é patológica.

$\mathrm{O}$ estudo da transexualidade, segundo Stoller (1993), contesta as teorias freudianas a respeito do desenvolvimento sexual. Como ponto de partida, Stoller vai contra a tese da bissexualidade originária, do caráter eminentemente masculino da libido e do papel preponderante do complexo de Édipo na formação da identidade sexual.

Freud (1905/1972, p.226) declara que todo ser humano nasce bissexual, apresentando um misto de traços de caráter masculino e feminino. Stoller se opõe a tal concepção composta, universalista e constitucional da sexualidade humana. Os transexuais masculinos, por exemplo, atestariam que sua identidade sexual sempre foi única, feminina.

De forma geral, pode-se dizer que em Freud a masculinidade é o estado primeiro: a libido é única, masculina, e o falo, masculino, tem estatuto de premissa universal. Contra tal postulado, Stoller (1982) formula a proposição da feminilidade primária: este seria o estado inicial e comum a todos, fruto da qualidade simbiótica do vínculo primordial estabelecido entre mãe e filho. Tal laço cria necessariamente um efeito feminino, que a menina não precisa superar, já que deve ser feminina, mas o menino sim, para se tornar masculino. Para ingressar no conflito edipiano, o menino deve superar esta primeira ligação simbiótica feminilizante.

O complexo de Édipo é um processo a ser atravessado e que leva o sujeito a se posicionar sexualmente, ou do lado masculino ou do feminino, finalmente identificando-se com os membros do seu próprio sexo e tomando o membro do sexo oposto como seu objeto sexual.

Segundo Stoller (1982), frente à perspectiva ameaçadora do Édipo normal, o menino opta por preservar não só o símbolo de sua virilidade, o pênis, mas principalmente sua identidade como homem. Nada disso é observado no sujeito transexual: na concepção stolleriana, a masculinidade não foi desenvolvida e o conflito edipiano está ausente.

O Édipo pressupõe a separação entre mãe e filho, promovida pela intrusão de um terceiro, o pai. No caso do menino transexual, o pai não interfere na relação mãe-filho-estes permanecem conectados. Consequentemente, o filho é condenado à feminilidade primária, não tomando sua mãe como objeto sexual, nem seu pai como objeto de identificação (Stoller, 1982). 
Neste sentido, Stoller considera que o fator mais importante para a formação da identidade sexual tem origem no período pré-edípico, e constrói a noção de núcleo de identidade de gênero. A transexualidade só pode ser pensada a partir do "mais primitivo estágio do desenvolvimento da masculinidade e da feminilidade, o núcleo da identidade genérica: o senso de pertencer ao sexo masculino ou feminino" (Stoller, 1982, p.292).

Fatores biológicos, biopsíquicos (na forma de impringting, condicionamento e aprendizagem) e psicológicos determinam a formação da identidade de gênero. Alterações intrínsecas a esses três fatores podem influir no desenvolvimento da identidade, fazendo com que esta entre em desacordo com o sexo anatômico (Stoller, 1993). São os aspectos psicológicos que o interessam como pesquisa e, para tanto, Stoller se volta para a transexualidade, justamente por considerar que a etiologia deste quadro clínico se deve principalmente a tais aspectos .

A partir de muitas observações clínicas, Stoller (1982) detecta um certo padrão na estrutura da família do sujeito transexual e na personalidade de seus membros. Há de acontecer uma rara coincidência de fatores, sendo todos eles imprescindíveis. São eles: uma mãe bissexual com um desejo parcialmente suprimido de ser homem e cronicamente deprimida; o filho é considerado muito bonito e gracioso, mantido muito perto dela, física e emocionalmente; o pai não rompe este laço simbiótico.

Não se trata aqui da simbiose comum que ordinariamente se estabelece entre mãe e filho. $\mathrm{Na}$ transexualidade masculina, Stoller (1982) denomina-a como simbiose feliz: há adoração pelo filho; o contato físico entre eles é excessivo e se prolonga por muitos anos; ele preenche suas necessidades mais importantes, aliviando-a de sua depressão e solidão. E o que deve acontecer para que este filho, e não outro seja escolhido? Stoller (1982) aqui é enfático: este filho deve ser considerado veementemente belo. Toda esta constelação de fatores solidifica a identificação feminina, enquanto a masculina é impedida.

Stoller (1982) levanta suas hipóteses diagnósticas a respeito da transexualidade masculina. Trata-se de um "distúrbio profundo no ego corporal da criança, pelo que ele se sente como sendo de alguma forma mulher, apesar de ter conhecimento de que é um homem" (Stoller, 1982, p.54). A mãe do transexual não danifica o desenvolvimento do ego de seu filho, nem mesmo do ego corporal, exceto em relação ao senso de feminilidade. A transexualidade é marcada, então, por distúrbio egóico — não se trata de perversão ou psicose.

A perversão, segundo Stoller (1982), é marcada por um tipo específico de defesa empregada frente ao conflito edípico. Ora, na transexualidade, nem entrada no Édipo há. Quanto à psicose, Stoller toma Schreber como paradigma e se pauta na análise que Freud faz de suas memórias para mostrar justamente que a transexualidade não se ancora nesta estrutura clínica.

Schreber acreditava ter sido convocado por Deus a cumprir a missão de redimir o mundo e restituir à humanidade seu estado de beatitude. Para tanto, cabia a ele ser transformado em mulher. Importante frisar que não se tratava de um desejo de Schreber, mas de uma imposição inelutável proveniente da Ordem das Coisas.

Ao contrário do delírio schereberiano, o transexual sabe que não é possível transformar-se num ser do outro sexo e não alucina sua realidade anatômica. Além do mais, não se trata aqui de um dever paranóico, mas de um forte desejo seu de que seu corpo corresponda ao do sexo oposto. Como não reconstrói seu corpo à maneira psicótica, pede por uma intervenção médica que tornaria coerentes corpo e identidade sexual (Garcia, 2001).

Curiosamente, os trabalhos mais influentes desenvolvidos a partir da psicanálise lacaniana sobre a transexualidade tomam justamente a psicose como condição para o estabelecimento deste quadro clínico. Tratemos de alguns deles.

\section{Transexualidade e psicose}

O próprio Lacan (1971/2009) refere-se à obra de Stoller e critica sua teoria por não levar em conta a foraclusão do Nome-do-Pai, marca da estrutura psicótica, como determinante para a transexualidade:

Chama-se Sex and Gender [Sexo e gênero], de um certo Stoller. É muito interessante de ler, primeiro porque desemboca num assunto importante - o dos transexuais, com um certo número de casos muito bem observados, com seus correlatos familiares. Talvez vocês saibam que o transexualismo consiste, precisamente, num desejo muito enérgico de passar, seja por que meio for, para o sexo oposto, nem que seja submetendo-se a uma operação, quando se está do lado masculino. No livro vocês certamente aprenderão muitas coisas sobre o transexualismo, pois as observações que se encontram ali são absolutamente utilizáveis. Aprenderão também o caráter completamente inoperante do aparelho dialético com que o autor do livro trata essas questões, o que o faz deparar, para explicar seus casos, com enormes dificuldades, que surgem diretamente diante dele. Uma das coisas mais surpreendentes é que a face psicótica desses casos é completamente eludida pelo autor, na falta de qualquer referencial, já que nunca lhe chegou aos ouvidos a foraclusão lacaniana, que explica prontamente e com muita facilidade a forma desses casos. (Lacan, 1971/2009, p.30)

Safouan (1979) expõe sua visão sobre a transexualidade a partir da interpretação dos três casos de meninos transexuais que Stoller analisa em sua obra Sex and Gender (1968). Para Safouan (1979), não se trata, nestes casos, somente de feminilização, 
mas de uma convicção delirante de ser mulher. Sua principal crítica a Stoller se dá quanto o entendimento da figura-função do pai. Safouan (1979) entende que, para Stoller, o essencial da função paterna poderia ser resumida a isso: separar a mãe do filho e servir de modelo de identificação para o menino.

Já para Safouan (1979), a função paterna diz respeito à dimensão da linguagem, o crucial é que o pai seja integrado na ordem simbólica: o que garante o corte da simbiose mãe-filho é a intrusão de um significante, o Nome-do-Pai, e é só a partir dele que o sujeito pode se confrontar com a diferença sexual e se posicionar de um dos lados na partilha dos sexos, assumindo uma identidade sexual, masculina ou feminina.

Porém, no transexual, tal significante não incide:

Surdez ao significante que, do lado das mães, condiciona a espécie de clausura ou de simbiose que elas tentam realizar com seus filhos. Assim, é tirado destes últimos o apoio do significante mesmo, em torno do qual deveria se fazer para um a assunção de seu próprio sexo (Safouan, 1979, p.83).

Desta forma, aquela simbiose estabelecida entre mãe e o filho transexual, "aquela plenitude delirante do real (....) não terá ocorrido sem acarretar uma foraclusão do Nome-do-Pai” (Safouan, 1979, p.92). Daí, nesta vertente de pensamento, a experiência transexual ter como condição diagnóstica a psicose.

Asolicitaçãopelas intervenções hormonocirúrgicas seria uma tentativa de inscrição na diferença dos sexos. O transexual apelaria para a castração no real do corpo, já que a castração simbólica lhe seria impossibilitada: "a castração foracluída nesses meninos como castração simbólica, aparece como castração real que os transexuais reclamam com uma paixão que nada tem de brincadeira (...)" (Safouan, 1979, p.92-93). Ou seja, o transexual "erra", como diz Lacan (1971/1972), por acreditar que uma operação no corpo daria conta de uma operação que só se pode dar no plano da linguagem.

Czermak (1991) inclui nesta discussão o papel da beleza e da vestimenta na encarnação que o transexual faz d'A mulher:

Não falei antes da estrutura da foraclusão, mas o que foi dito anteriormente leva, com certeza a este conceito. Resumindo: tentei mostrar inicialmente como, nas pessoas de que falei, surge a partir da tentativa de rejeitar o significante fálico, o dever de ser mulher para si mesmo. Esse dever instaura o caminho de uma demanda sem nada além, de uma exigência petrificada e, segundo o erro comum, de uma mudança morfológica que atinge os órgãos exigência endereçada a um médico encarado como não barrado. Tal rejeição visa produzir a superação, um tipo de forçagem do Real, da Identificação à unificação e à superação que lhe é homogênea, do fantasma do falo à beleza, e que leva à tendência assintótica na direção d'A mulher, que é um dos
Nomes-do-Pai, cuja tradução delirante é um colapso do corpo na vestimenta, em um autêntico delírio do envoltório. (Czermak, 1991, p.95)

Frignet (2002) contribui para a pesquisa do tema ao estabelecer a diferença entre o sujeito transexual e o transexualista, que revela um segmento do fenômeno transexual não enraizado na psicose. Frignet (2002) aponta a importância de abordar a experiência transexual como fenômeno cultural, levando em conta a influência proporcionada pela resposta social de grande interesse que a acompanha. O transexualista, e não o sujeito transexual, é justamente um sujeito movido à obtenção de um tipo de gozo resultante da alienação imaginária a determinado grupo social. Contudo, transexual ou transexualista, não se escapa da tendência à patologização: o transexual é psicótico e o transexualista se aproxima da perversão.

Desta forma, esses importantes autores lacanianos, a partir de diferentes ferramentas teóricas, sustentam que a transexualidade é determinada pela psicose, destinada ao campo da patologia. Na sequência deste trabalho, pensaremos a transexualidade lançando mão da teoria do estádio do espelho desenvolvida por Lacan e do mecanismo da Verleugnung como tentativa de deslocá-la do imperativo arcabouço teórico regido pelo Verwerfung e a forcaclusão do Nome-do-Pai. Cabe desde já apontar que não pretendemos reduzir toda experiência transexual, ampla e complexa, ao funcionamento da Verleugnung, mas destacar que tal dinâmica pode também estar em jogo na transexualidade, afastando-a da restrição diagnóstica a que foi submetida pela tradição psicanalítica, o que contribuiria para a desarticulação da totalidade da manifestação deste quadro clínico do campo da psicopatologia psicanalítica.

\section{Transexualidade e estádio do espelho.}

Como dito anteriormente, Stoller (1982) não atrela a transexualidade à psicose ou à perversão, apesar de ainda referi-la à psicopatologia. Seu estatuto diagnóstico seria o de uma problemática a respeito do registro imaginário do corpo, cuja sede por excelência é a instância do ego. Exploremos um pouco mais tal idéia.

Sobre o ego corporal, Freud coloca: "Assim, o Eu é sobretudo um Eu corporal, mas ele não é somente um ente de superfície: é, também, ele mesmo, a projeção de uma superfície" (Freud, 1923/2007, p. 38). Em uma nota de rodapé, acrescenta: "Isto é, em última instância, o Eu deriva de sensações corporais, basicamente daquelas que afloram da superfície do corpo. Ele pode ser considerado então, como uma projeção mental da superfície do corpo, além de representar a superfície do aparelho mental" (Freud 1923/2007, p. 83). O Eu se forma, então, a partir de sensações corporais, tanto pulsionais como provenientes da realidade externa. A imagem que o Eu forma do corpo deriva de tais sensações. Segundo 
Ceccarelli (2008), a formação do Eu está atrelada a toda superfície corporal erogeneizada. Espera-se que se estabeleça uma correspondência minimamente estável entre a instância egóica e o corpo anatômico, do qual as sensações constitutivas do Eu emergem.

Contudo, pode ser que as representações psíquicas referentes a sensações de algumas partes do corpo sejam perturbadas, não sendo consequentemente erogeneizadas. Neste sentido, segundo Ceccarelli (2008), pode-se considerar que certas partes do corpo do transexual (principalmente seu órgão sexual) não foram investidas libidinalmente durante o período auto-erótico e do narcisismo primário - daí serem indesejadas e repelidas. O Eu dos transexuais percebe as sensações emitidas por tais regiões do corpo como algo desprazeroso. Contudo, isso não quer dizer que o órgão sexual não seja representado psiquicamente. Não se trata de dissociação psíquica ou de recusa desse elemento, mas sim de narcisismo negativo, tal como denominou Ceccarelli (2008, p. 161).

A teoria da constituição do ego corporal nos parece compatível com a teoria de estádio do espelho proposta por Lacan (1949/1998).

A fase do espelho corresponde ao advento do narcisismo primário; é o primeiro momento da construção identitária. A identificação imaginária diz respeito ao nascimento do $\mathrm{Eu}$ : a criança se identifica com sua imagem produzida pelo espelho. Em um momento de prematuridade do sistema nervoso, a criança antecipa imaginariamente uma imagem unificada do seu corpo, configurando o primeiro esboço da formação do ego e abrindo as portas para as identificações secundárias. $\mathrm{O}$ essencial quanto à assunção da imagem do corpo produzida pelo espelho é que o Outro autentique para a criança que tal imagem corresponde ao corpo dela. E se a imagem proposta investe libidinalmente o corpo da criança de forma perturbada? $\mathrm{Na}$ psicose, parece não haver tal integração entre imagem e corpo, e o sujeito sofre de profundas angústias de fragmentação. Esse não é o caso da transexualidade.

Na visão de Ceccarelli (2008, p.110-114), neste momento em que a imagem da criança deveria ser consentida pelo Outro, na transexualidade há um momento de hesitação, uma derrapagem: por mais que o sexo do bebê tenha sido reconhecido pelo Outro, uma denegação se produz — tal imagem, ao mesmo tempo que é reconhecida, é negada — , fazendo com que partes de seu corpo, justamente as que denunciam a que sexo pertence, não tenham sido investidas libidinalmente. A criança responde em sua fantasia ao desejo do Outro se identificando com o que viu no olhar do Outro, no caso sua imagem configurada como sendo do sexo oposto. Apesar de Ceccarelli não se referir explicitamente ao termo, este mecanismo de denegação a que alude nos parece compatível com o da Verleugnung freudiana.

Seguindo este caminho, podemos então considerar o mecanismo da Verleugnung como também em jogo na transexualidade. O sujeito transexual não distorceria a percepção de seu corpo. Contudo, ela traria a tona afetos intoleráveis, daí a tentativa de negar sua presença, desmentindo sua imagem corporal. Cabe salientar que aqui não há Verwerfung da anatomia, mas sim, a nosso ver, Verleugnung.

Passemos então a um breve estudo da Verleugnung em Freud para depois, a partir dos inovadores trabalhos de Figueiredo (2008) e Pereda (1999), relacioná-la à transexualidade.

\section{Transexualidade e Verleugnung}

$\mathrm{O}$ verbo verwerfen refere-se a rejeitar, descartar, não aceitar, considerar inadequado; enfatiza o descarte. Aqui, a resolução é definitiva: o sujeito se livra do material, que é eliminado (Hanns, 1996, p. 373). Depois de 1918, Freud quase não mais emprega o termo verwerfen (e o substantivo verwerfung), voltando-se sistematicamente a verleugnen (Penot,1992, p. 39). Pode-se inclusive considerar que, ao longo da obra de Freud, também o alcance do recalque foi se reduzindo, ao passo que a incidência da Verleugnung foi ganhando espaço.

Verleugnung pode ser traduzido por renegacão, recusa ou desmentido. Tal conceito possui grande complexidade e ocupa um lugar importante na teoria freudiana. Ao longo de sua obra, foi usado em contextos diferentes: inicialmente concebido como uma postura que a criança assume diante da castração no Édipo normal, passando a ser atrelado ao funcionamento psicótico, depois ao fetichismo e, finalmente, à neurose comum.

Seu verbo correspondente diz respeito a um tipo específico de negação que se aproxima de anular a própria presença, desmentir algo, agir contra a própria natureza. É uma tentativa de negar algo afirmado ou admitido outrora, como se o sujeito soubesse que aquilo que é rejeitado existe, mas continuasse a negar sua presença.

Cabe salientar que o material rejeitado não é definitivamente eliminado, exigindo um esforço contínuo para manter a negação. O Eu levanta defesas frente a estimulações decorrentes do mundo interno, e também do externo, estímulos estes que trazem à tona lembranças, fantasias ou afetos insuportáveis. Distúrbios de percepção podem ser erigidos como mecanismos de defesa. Defrontado a uma realidade insuportável, quatro atitudes poderão ser tomadas: modificar sua percepção, criando uma ilusão; tornar tal percepção inconsciente por tempo indefinido (alucinação negativa); perceber aquilo que não existe (alucinação positiva); ou cindir-se frente à realidade, reconhecendo-a e recusando-a, o que corresponde ao termo renegação (Bourguignon, 1991, p. 60). Nesse caso, há clivagem do Eu: uma parte reconhece a realidade e a outra a renega, simultaneamente.

Desde 1905, Freud anunciara que frente à 
ausência de pênis da mulher, a criança, ameaçada pela castração, tenderia a rejeitar a percepção de tal ausência, o que abriria caminho para elaborações secundárias e as teorias sexuais infantis. Contudo, o conceito de renegação ou recusa sob o termo Verleugnung só é diretamente relacionado por Freud à castração em 1923. Posteriormente, em 1924, tal mecanismo é vinculado à psicose. A recusa se daria como extirpação de um traço qualquer da realidade exterior.

Em 1927, Freud abordou este mecanismo a partir do fetichismo. Confrontado com a ausência do falo materno, o sujeito faria aqui com que duas realidades conflitantes coexistissem - a percepção da tal ausência e sua consequente negação, conservando a crença de que a mulher tem o falo. Freud conclui que para que tais representações psíquicas incompatíveis coexistam no aparelho psíquico sem se influenciarem, o Eu deverá ser necessariamente clivado (Freud, 1927/2007, p.159-170]). Contudo, a clivagem do Eu não se restringe à perversão. Freud, em 1940[1938], generaliza tal propriedade ao nível do funcionamento psíquico neurótico:

Os fatos desta divisão do ego, que acabamos de descrever, não são nem tão novos nem tão estranhos quanto podem a principio parecer. É, na verdade, uma característica universal das neuroses, que estejam presentes na vida mental do individuo, em relação a algum comportamento particular, duas atitudes diferentes, mutuamente contraditórias e independentes uma da outra (Freud,1975/1940[1938], p. 234).

A Verleugnung pode então também ser encarada como um mecanismo de defesa acessório da neurose, que pretende não tomar conhecimento das percepções externas cujo conteúdo reativa o material recalcado. É o Lacan da década de 50 (seminários III, IV e V, principalmente) quem fará com que a Verleugnung seja tomada como elemento diagnóstico diferencial entre as estruturas clínicas. A partir disso, tal modo de negação corresponderá à estrutura perversa. Contudo, já em Freud, seu alcance é maior: "A rigor não se pode considerar a Verleugnung, em Freud, um mecanismo exclusivo da perversão: Freud o emprega em um sentido genérico de negar uma evidencia intolerável" (Hanns, 1996, p. 312). A Verleugnung pode, então, ser encarada como mecanismo em jogo para além da trama edípica e da determinação diagnóstico de uma clínica estrutural. Como recurso do psiquismo comum, também pode ser usado para se pensar a transexualidade.

O relato da transexual Katia (in Bento [2006, p.183]) serve de ilustração de como tal mecanismo pôde estar em jogo na sua experiência:

Só vim a conhecer meu corpo aos 14 anos, quando vi uma revista pornográfica embaixo do colchão do meu irmão e vi uma mulher sem roupa. Eu já tinha visto meus irmãos pelados com o pênis duro, mas o meu era aquela coisinha pequenininha, nunca subiu.
Para mim, toda mulher era daquele jeito. Eu estava esperando meus seios crescerem, porque minhas amigas estavam de peito grande e eu não. Nelas, veio a menstruação e em mim não, né? Então, eu fiquei preocupada com aquilo. E outra, eu entrei na escola com 18 anos. Eu abandonei a família e fui morar com meu tio na cidade. Na escola é que se descobre. Ai, com 18 anos, procurei uma médica e perguntei para ela. Eu queria saber porque todas as minhas amigas tinham a menstruação. Os peitos delas eram grandões e o meu era pequeno, só duas bolinhas. Então, eu queria perguntar o porquê de tudo aquilo. $\mathrm{Eu} \mathrm{me}$ sentia uma mulher, agia como mulher. Quer dizer, que nem uma mulher (...).

Desta forma, nota-se nas palavras de Kátia que, ao mesmo tempo que reconhecia, com o avanço da puberdade e as crescentes evidências, seu corpo não correspondia a sua identidade sexual ou à imagem que tinha de si, ela ainda mantinha uma certa forma de negação desta percepção sustentando a crença de que seu corpo ainda fosse se desenvolver na direção da feminilidade. Neste sentido, parecia conhecer e desconhecer "a verdade do seu corpo", nos termos de Bento (2006, p.185). Só mais tarde, após consultarse com um médico, sua situação se esclareceu para ela, com terror: "A coisa é horrível, porque você vê que não era aquilo que imaginava, que você pensava que era. Eu ia me matar" (in Bento [2006, p.185]). A experiência de Kátia diverge da experiência transexual expressa por sujeitos psicóticos, tal como se constata claramente em grande parte literatura psicanalítica lacaniana sobre o assunto [cf. Safouan (1979); Czermak (1991) e Frignet (2002)]. Nestes casos, verifica-se que ou o sujeito padece de alucinações de que o seu corpo está sendo alterado, mesmo transformado no corpo do outro sexo, como atesta o delírio transexual de Schreber em que Deus exigia sua "transformação em mulher para vir gozar de seu corpo, com o objetivo de vir procriar uma nova raça de homens, parodiando assim o casal derradeiro de sobreviventes da terra" (Quinet, 2000, p.23), — ou o sujeito tende a afirmar desde muito cedo habitar o corpo errado e, anos mais tarde, sustentar a ficção de ter a certeza de pertencer ao outro sexo, agarrandose à ideia de que os tratamentos hormonocirúrgicos restituiriam sua verdade, permitiriam uma espécie de renascimento e completude. Ora, a sexualidade humana é marcada pela indeterminação pulsional, daí o sujeito neurótico pôr em dúvida sua localização no campo sexual - a certeza neste terreno aponta para o delírio. De toda forma, como quisemos demonstrar com a ilustração clínica acima, uma experiência transexual regida pela Verleugnung apresenta drásticas diferenças quando comparada à sua manifestação na psicose.

O trabalho de Figueiredo (2008) traz novos ares para a pesquisa da Verleugnung, a partir do qual podemos conjecturar a experiência transexual de 
alguns sujeitos. Figueiredo (2008) opta pelo termo "desautorização" para se referir à Verleugnung, enfatizando seu caráter de "interrupção de um processo pela eliminação da eficácia transitiva de um dos seus elos" (Figueiredo, 2008, p.59). O que se recusa não é uma determinada percepção, mas o que vem depois dela, uma conclusão lógica necessária ou uma lembrança reativada pela percepção. O que se desmente não é o significado da percepção, aquilo que se vê, mas o que se poderia inferir a partir dela, a consequência desse saber. Neste sentido, a percepção é desfalcada de autoridade para encadear outras percepções e outros processos psíquicos, mantida isolada da conexão de outros processos mnêmicos e de simbolização. A percepção não perde significado, mas significância, ou seja, o processo de simbolização não é impedido por completo, porém o significado é retirado de uma rede de associações para ser preservado como uma quase-coisa, como uma lembrança que não se integra ao fluxo psíquico por ter perdido a sua capacidade de metaforização.

Em última instância, o objetivo da desautorização é a esquiva da continuidade do processo perceptivo, de uma lembrança ou da uma conclusão traumática, o que gera tensão entre a corrente que exige novas percepções e conclusões inevitáveis e outra que estanca a cadeia congelando-a em uma percepção primordial, o que aprisiona o sujeito na repetição do mesmo e o faz recuar frente à diferença. $\mathrm{Na}$ transexualidade, podemos então conjecturar que a percepção do corpo do sujeito é aceita, mas desautorizada, impedindo a conseqüência metafórica de tal percepção. Então, o sujeito fica preso à idéia de que seu posicionamento na partilha dos sexos deva ser confirmado na materialidade corpórea, confinado que está na percepção visual primária da diferença anatômica dos sexos-neste sentido, a diferença sexual não chegou a se inscrever na continuidade das sequências simbólicas.

O corpo do sujeito transexual (mais enfaticamente as partes que denunciam a que sexo pertence) permanece no estado de quase-coisa, não metaforizada, daí o sujeito intervir diretamente nele, não à maneira psicótica, mas sim sob o mecanismo de desautorização, como forma de assumir seu sexo e chegar a um maior reconhecimento de si.

Pereda (1999) também apresenta um trabalho muito interessante a respeito da Verleugnung, alçando o mecanismo do desmentido ao modo de funcionamento predominante da sociedade atual. Como toda estruturação psíquica inclui (e reflete) o contexto social na qual emerge, uma sociedade regida pela Verleugnung traria graves conseqüências para o sujeito.

O desmentido, na visão de Pereda (1999), comporta duas dimensões: por um lado, é um mecanismo normal e estruturante do psiquismo, tal como se lê no final da obra freudiana; é um mecanismo básico e saudável de defesa da castração lançado mão em um momento em que a criança ainda não tem recursos simbólicos mais consistentes - o que leva o sujeito se sustentar no imaginário e se alienar no outro. No desmentido estrutural, não há fetichismo ou formações delirantes. A cisão que o marca, Pereda (1999) nem mesmo a considera uma verdadeira cisão, já que só incidiria na díade saber-não saber da castração, conhecimentodesconhecimento, reiterando a divisão conscienteinconsciente.

Por outro lado, o desmentido comporta uma dimensão patológica. Nas novas patologias da atualidade, haveria de fato uma cisão egóica — de onde decorre a abundância das convicções e de sua contrapartida, a desconfiança; crer em tudo e não crer em nada. Tais crenças se tornam convicções desprendidas de amarras simbólicas, gerando cisões e convocando o sujeito a produzir próteses que o protegeriam de arrombos caóticos.

$\mathrm{Na}$ pós-modernidade, segundo Pereda (1999), há grande flexibilização e multiplicação das identidades e, ao mesmo tempo, uma grande possibilidade de apagamento das diferenças - vemos aqui o mecanismo da Verleugnung, a partir da qual antinomias convivem, em ação no social. Tais mudanças promoveriam novas formas de se lidar com os conflitos psíquicos e reformulariam as formas de se posicionar frente a organizadores inconscientes como a diferença sexual. Sexualidade, libido, desejo e defesa, baluartes da psicanálise, sempre foram submetidos a regulamentações simbólicas, que, por sua vez, ancoram o sujeito na cultura. Para Pereda (1999), no momento atual, tais regulamentações simbólicas são abaladas, produzindo um transtorno simbólico do pensamento (ou transtorno do processo de simbolização) em quadros clínicos atuais que, em certa medida, acomodam-se bem à polimorfia das realidades sociais. Ao lado do desmentido, subsistem mecanismos defensivos narcisistas, identificações frágeis e a dependência visceral do reconhecimento do outro (não o reconhecimento do Outro simbólico).

É curioso que, no contexto atual de multiplicidade sexual e da exigência de legitimidade das diferenças, muitos sujeitos transexuais se esforçam ao máximo para se adequar às normas heterossexuais tradicionais de correspondência entre sexo e gênero, indo contra a experiência de viver a descontinuidade de tais fatores. Além do mais, muitas de suas reivindicações por reconhecimento se dão a partir da imagem a ser configurada via intervenções feitas diretamente no corpo, imagem esta que pretenderia dar consistência à ilusão de substância da identidade sexual. Podemos dizer que certos sujeitos transexuais, adotando a linha de raciocínio de Pereda (1999), ficariam reféns do reconhecimento do outro, tornando-se dependentes do objeto e da fragilidade imaginária que propõe, refletindo o modelo de funcionamento sustentado pela Verleugnung nos dias de hoje. Podemos considerar 
que tais transexuais sabem disso, mas não querem saber? Como se dissessem: --“eu sei que não é uma intervenção no corpo o que me faria homem ou mulher, nem o reconhecimento do outro, mas mesmo assim..."

Pensar o mecanismo da Verleugnung nos desenvolvimentos de Pereda (1999) traz novidades. Primeiro, porque é tratado como um modo de funcionamento psíquico privilegiado pelo funcionamento da própria sociedade, e não como um mecanismo de defesa determinante e intrínseco ao sujeito perverso, ao qual sempre se articulou ares pejorativos, tal como se nota na tradição psicanalítica. Segundo, porque certa experiência transexual poderia ser induzida por tal funcionamento, mas não só ela, o que se verificaria também em novos desdobramentos do narcisismo, inéditos fenômenos de alienação e reconhecimento, ou seja, seria mais uma dentre as diversas derivações das inescapáveis e constantes reconfigurações sociais. Terceiro, porque se trata de um mecanismo comum a todos, não é marca determinante de alguma entidade psicopatológica, tal como é a Verwerfung para a psicose, por exemplo.

De toda forma, abordar a transexualidade via Verleugnung, mecanismo em ação em todo sujeito e que opera com força no social, desloca este quadro clínico da concepção que sempre relegou tais sujeitos ao campo do distúrbio e, dentro da psicanálise lacaniana, ao diagnóstico de psicose. Tal proposta possibilita não mais reduzir o fenômeno transexual a generalizações precárias e, além disso, deslocá-lo do campo psicopatológico.

\section{Referências}

Benjamin, H. (1966). The transsexual phenomenom, ( $1^{\mathrm{a}}$ ed. em inglês). Nova Iorque: Julian Press.

Bento, B. (2006). A Reinvenção do corpo: sexualidade e gênero na experiência transexual, $\left(1^{\mathrm{a}} \mathrm{Ed}\right.$.). Rio de Janeiro: Garamond.

Bourguignon, A. (1991). O conceito de renegação em Freud e outros ensaios, ( $1^{\text {a }}$ ed.). Rio de Janeiro. Jorge Zahar Ed.

Ceccarelli, P. R. (2008). Transexualismo, (1 $1^{\mathrm{a}}$ ed.). São Paulo: Casa do Psicólogo.

Chemama, R. \& Vandermersch, B. (2007). Dicionário de Psicanálise, (1 ${ }^{\mathrm{a}}$ ed.). São Leopoldo-RS, Editora Unissinos.

Czermak, M. (1991). Paixões do objeto: estudo psicanalítico das psicoses, $\left(1^{\mathrm{a}}\right.$ ed.). Porto Alegre, Artes Médicas.

Figueiredo, L. C. (2008). Psicanálise: elementos para a clínica contemporânea, ( $1^{\mathrm{a}}$ ed.). São Paulo: Escuta.

Freud, S. (1905/1972). Três ensaios sobre a teoria da sexualidade. In: Edição standard brasileira das obras psicológicas completas de Sigmund Freud. v. VII (pp.123-251). Rio de Janeiro: Imago. (Trabalho original publicado em 1905).

Freud, S. (1923/2007). O Eu e o Id. In Escritos sobre a psicologia do inconsciente. v. III (pp. 13-92). Rio de Janeiro: Imago. (Trabalho original publicado em 1923).

Freud, S. (1927/2007). Fetichismo. In Escritos sobre a psicologia do inconsciente. v. III (pp. 159-170). Rio de Janeiro: Imago. (Trabalho original publicado em 1927).

Freud, S. (1938[1940]/1975). Esboço de psicanálise. In Edição standard brasileira das obras psicológicas completas de Sigmund Freud. v.XXIII (pp. 133-210). Rio de Janeiro: Imago. (Trabalho original publicado em 1975).
Frignet, H. (2002). O transexualismo, ( $1^{\mathrm{a}}$ ed.). Rio de Janeiro: Companhia de Freud.

Garcia, J. C. (2001). Problemáticas da identidade sexual, ( $3^{\mathrm{a}}$ ed.). São Paulo: Casa do Psicólogo.

Hanns, L. (1996). Dicionário Comentado do Alemão de Freud, ( $1^{\mathrm{a}}$ ed.). Rio de Janeiro. Imago, Ed.

Lacan, J. (1998). O estádio do espelho como formador da função do eu, In Escritos (pp. 96-103). Rio de Janeiro: Jorge Zahar Ed, (Comunicação feita em 1949).

Lacan, J. (1998). A significação do falo, In Escritos, (pp. $692-$ 703). Rio de Janeiro: Jorge Zahar Ed, (Conferência proferida em 1958).

Lacan, J. (1999). O Seminário, livro 5: as formações do inconsciente. ( $1^{\mathrm{a}}$ ed.). Rio de Janeiro: Jorge Zahar Ed, (Seminário ministrado em 1957-1958).

Lacan, J. (2009). O Seminário, livro 18: de um discurso que não fosse do semblante, ( $1^{\mathrm{a}}$ ed.). Rio de Janeiro: Jorge Zahar Ed, (Seminário ministrado em 1971).

Penot, B. (1992). Figuras da recusa-aquém do negativo, (1 ed.). Porto Alegre: Artes Médicas, 1992.

Pereda, M. C. (1999). En el camino de la simbolización: producción del sujeto psíquico, ( $1^{\mathrm{a} e d . e m ~ e s p a n h o l) . ~ B u e n o s ~ A i r e s . ~}$ Paidós.

Quinet, A. (2000). Teoria e clínica da psicose. (2 ed.). Rio de Janeiro: Forense Universitária.

Roudinesco, E \& Plon M. (1998). Dicionário de psicanálise, ( $1^{\text {a }}$ ed.). Rio de Janeiro: Jorge Zahar Ed.

Saadeh, A. (2004). Transtorno da identidade sexual: um estudo psicopatológico de transexual ismo masculino e feminino. Tese (Doutorado em Medicina) - Departamento de Psiquiatria, Faculdade de Medicina da Universidade de São Paulo. São Paulo.

Safouan, M. (1979). Estudos sobre o Édipo: introdução a uma teoria do sujeito, ( $1^{\mathrm{a}}$ ed.). Rio de Janeiro, Zahar Editores.

Stoller, R. J. (1982). A experiência transexual, (1 ${ }^{\mathrm{a}}$ ed.). Rio de Janeiro: Imago.

Stoller, R. J. (1993) Masculinidade e feminilidade: apresentação de gênero, $\left(1^{\mathrm{a}}\right.$ ed.). Porto Alegre: Artes Médicas. 
Sobre o autor:

Rafael Kalaf Cossi - Psicólogo e psicanalista. Doutorando do Departamento de Psicologia Clínica IPUSP. Mestre pelo Departamento de Psicologia Clínica-IPUSP. Especialista pelo curso "Teorias, técnicas e estratégias especiais em psicanálise"-IPUSP. Membro do Laboratório de Teoria Social, Filosofia e Psicanálise (LATESFIP-USP). Autor do livro "Corpo em obra: contribuições para a clínica psicanalítica do transexualismo", nVersos Ed.

E-mail: rkcossi@hotmail.com 